\title{
EVALUATION OF MICROMECHANICAL PROPERTIES OF CARBON FIBER FABRIC USING NANOINDETATION
}

\author{
Pavel Klapálek $^{a, *}$, ZdeněK ProšeK ${ }^{a, b}$, Aleš Jíra $^{a}$, Lenka Melzerová ${ }^{a}$ \\ ${ }^{a}$ Czech Technical University in Prague, Faculty of Civil Engineering, Thákurova 7, 16629 Prague 6, Czech \\ Republic \\ ${ }^{b}$ University Centre for Energy Efficient Buildings, Czech Technical University in Prague, Třinecká 1024, \\ 27343 Buštěhrad, Czech Republic \\ * corresponding author: pavel.klapalek@fsv.cvut.cz
}

\begin{abstract}
This paper is focused mainly on nanoindentation of carbon fibers. Fibers are in form of carbon fiber fabric that is used in larger research that is focused on reinforcing beams made of glued laminated timber. Knowledge of this material on macro and micro level will help to understand its behavior in this specific type of use. Nanoindentation is method used in this paper to obtain material characteristics on micro level such as hardness and modulus of elasticity. Samples of the carbon fiber fabric had to be prepared for this specific testing method by polishing samples of carbon fabric attached in epoxy resin. In particular, it was found that the indentation hardness of the fibers ranges around $3.65 \mathrm{GPa}$ and modulus of elasticity ranges around $26 \mathrm{GPa}$.
\end{abstract}

KEYWORDS: carbon fiber fabric, nanoindentation, micromechanical properties.

\section{INTRODUCTION}

This paper is part of extensive research focused on reinforcing glued laminated timber beams with use of carbon fiber fabric. Because in nowadays civil engineering is the timber very popular material, as it is on rise again mainly because of the high demands on energy efficiency of buildings, it is appropriate to devote this material to try to find ways for its optimum utilization. When solid timber ceased to meet the demands of civil engineers, it was necessary to find a way to improve its performance. Accordingly, there was also first thought to remove these drawbacks by means of gluing timber elements to create a composite material with better properties than solid timber. That is glued laminated timber [1]. It consists of layers of lamellas that are glued together under pressure, using a waterproof adhesive [2]. At present, this material is mainly used in modern timber structures and roof structures of halls. Despite the frequent use of this material, the technology of production is still in development. For this reason, the main material, which is an essential part of this research is glued laminated timber reinforced with carbon fiber fabric. As we examined timber with nanoindentation before [3, 4], there was a need for values from carbon fibers [5]. Carbon fibers history goes back to 1860, where Joseph Swan produced carbon fibers for the first time, for use in light bulbs [6]. In 1879, Thomas Edison baked cotton threads or bamboo slivers at high temperatures carbonizing them into an all-carbon fiber filament used in one of the first incandescent light bulbs to be heated by electricity [7. But first real use in industry started in 1960 when Richard Millington of H.I. Thompson Fiberglas Co. developed a process
(US Patent No. 3,294,489) for producing a high carbon content (99\%) fiber using rayon as a precursor. These carbon fibers had sufficient strength (modulus of elasticity and tensile strength) to be used as a reinforcement for composites having high strength to weight properties and for high temperature resistant applications. In the coming years there were a lot of improvement in manufacturing processes and nowadays the carbon fibers are used in many sectors of industry (mostly in aviation, cars, composite materials etc.). Carbon fiber fabric combined with glued laminated timber seems to be suitable for development in the civil engineering.

\section{TESTING}

\subsection{TESTED MATERIAL}

Tested material. Tested material was carbon fiber fabric that is used to reinforce glued laminated timber beams. This material was used for additional reinforcement of GLT beams on the bottom surface. Type of used fabric is Carbon unidirectional UD CST 200 made of unidirectional carbon fiber with PES grid. It has thickness of $0.4 \mathrm{~mm}$ and grammage of $200 \mathrm{~g} / \mathrm{m}^{2}$ (Figure 1).

Samples of carbon fiber fabric were photographed with use of a scanning electron microscope (SEM) to verify properties such as thickness and diameter of individual fibers. This carbon fiber fabric is made of layer of carbon fibers that are aligned in one direction. Figure 2 is detail of carbon fabric magnified $250 \times$ and alignment of individual fibers is evident. At figure 3 is bunch of individual fibers magnified $5.7 \mathrm{k} \times$, diameter of each fiber is around $6 \mu \mathrm{m}$. 


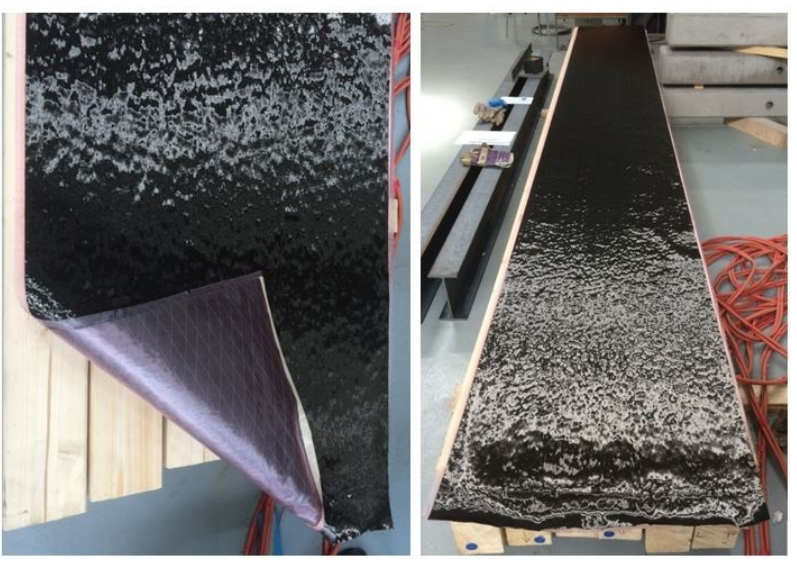

FiguRE 1. Second set of Glued laminated timber beams.

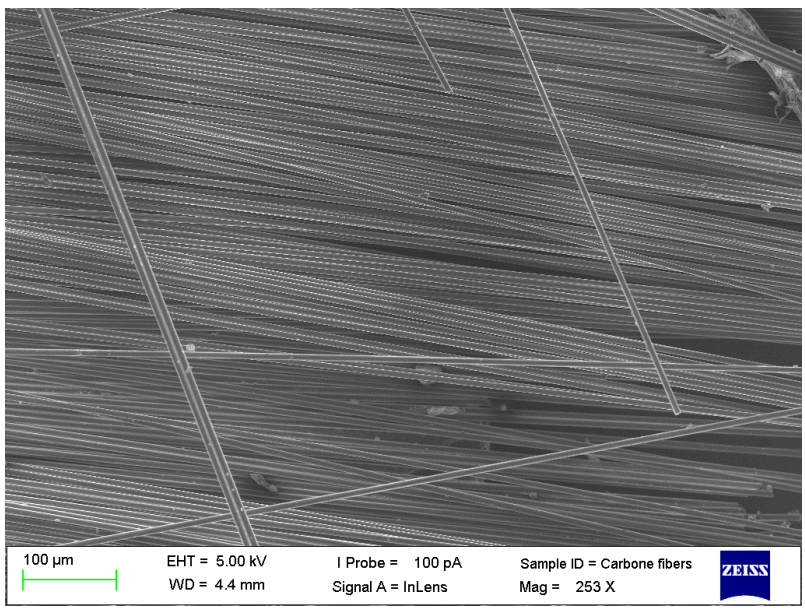

Figure 2. Carbon fiber fabric magnified $250 \times$.

To prepare samples of carbon fiber fabric for examination on nano/micro level with nanoindentation the polished slices had to be prepared. Before grinding of samples, the fibers had to be attached with suitable substance to avoid fraying of fibers during sample preparation. For this purpose, a method of vacuum impregnation with epoxy resin (EpoFix Kit) was used. Grinded cuts were prepared with machine Tegramin from company Struers located at University center of energy efficient buildings. Samples were grinded and polished in multiple steps to achieve the best quality of sample surface. In the first step, sandpaper with a grain size of 220 grains $/ \mathrm{cm}^{2}$ was used to eliminate the greatest unevenness after cutting. In the following steps, finer sandpaper was used: 500 grains $/ \mathrm{cm}^{2}, 1200$ grains $/ \mathrm{cm}^{2}, 2000$ grains $/ \mathrm{cm}^{2}$ and 4000 grains $/ \mathrm{cm}^{2}$. Each step lasted 5 minutes while water was used as a lubricant.

\subsection{Testing Method - StATiC NANOINDENTATION}

Nowadays is the static nanoindentation is widely used and it is a very popular experimental technique for measuring the elastic stiffness and hardness of various materials (glass, metal, wood, ceramics). Advantage

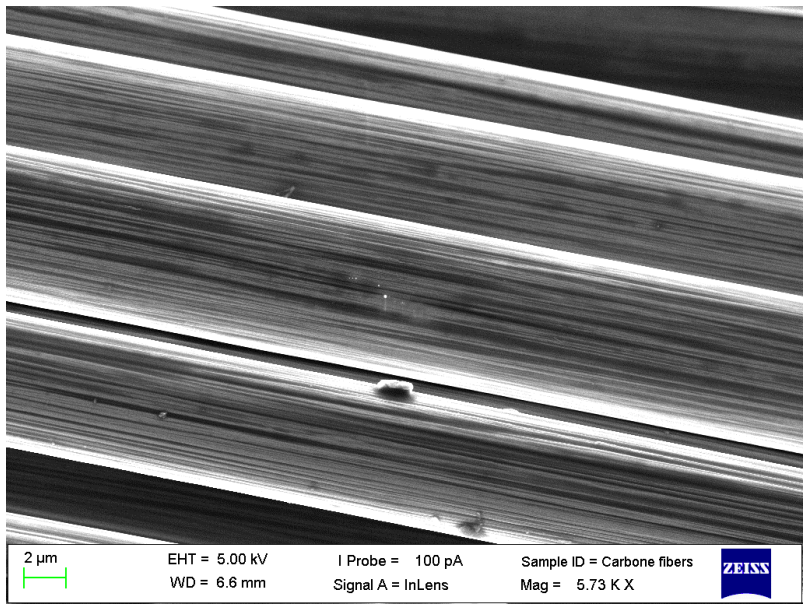

Figure 3. Carbon fiber fabric magnified $5.7 \mathrm{k} \times$.

of this testing method is that it can performed on a very small volume, so it is suitable for investigating materials at microscale. The principle is based on imprinting a micrometer sized diamond tip into the investigated material and recording the loading force and the indentation depth [8]. In most of the measurements, the indentation depth is in the order of hundreds of nanometers. There are various tips available for nanoindentation, e.g. Berkovich, wedge or spherical tips. Also, several techniques can be used to ensure that the analysis also provides information about the plastic hardening, the viscosity or the yield stress of the material [9]. Standardized data is based on the assumption of perfectly homogeneous isotropic material in offset volume, and elastic and non-elastic material parameters are usually derived from nanoindentation data using an analytical solution. The pioneering work of Hertz (1882) [10 dealt with the imprint of an elastic tip in a homogeneous medium. Sneddon (1965) 11 derived an analytical relationship between the loading force, the depth of an imprint and the contact area for individual indentation tips. Typical output of measured nanoindentations consists of two elastic constants: hardness and stiffness parameters. The hardness parameter is defined as the contact pressure diameter at maximum load. During deformation, the deformed material deforms in both the elastic and the plastic range. The plastic response on the load-pull curve is excluded during unloading, allowing the user to determine the stiffness of the material in the local environment known as the reduced modulus of elasticity (Figure 4 and 5 . The value for the reduced modulus can therefore be obtained from the unloading part of the recorded force-displacement diagram [12, 13].

\subsection{MeAsurement AND RESUlts}

Nanoindentation was performed by using a CSM Instruments device with wedge tip, located in at the Faculty of Civil Engineering at CTU in Prague. The results of the static loading are in set of nanoindentation curves. This curve describes the response of 


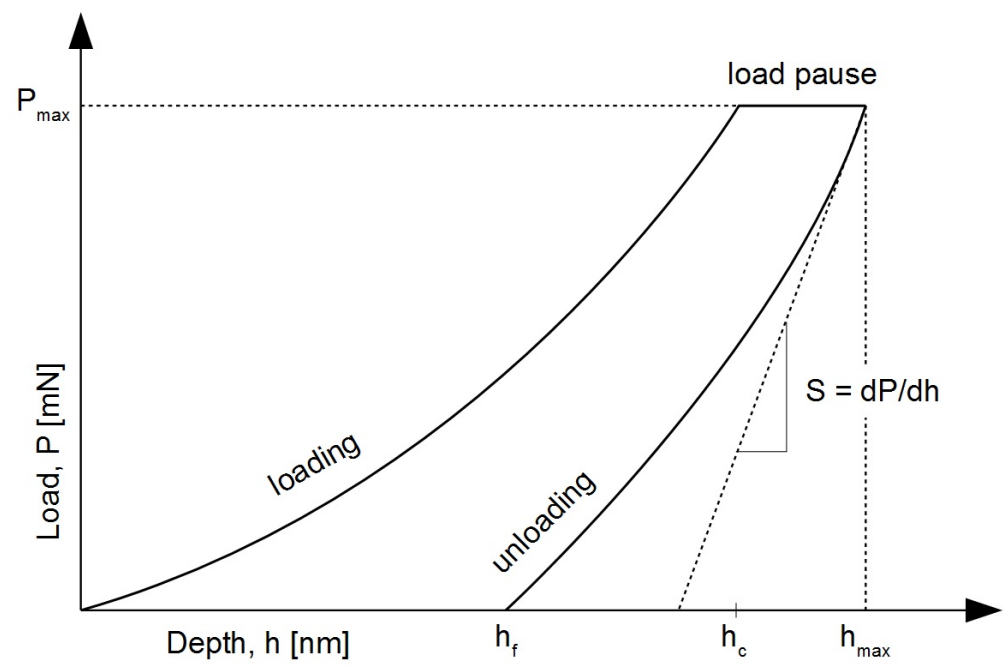

Figure 4. Typical indentation curve - load vs. depth.

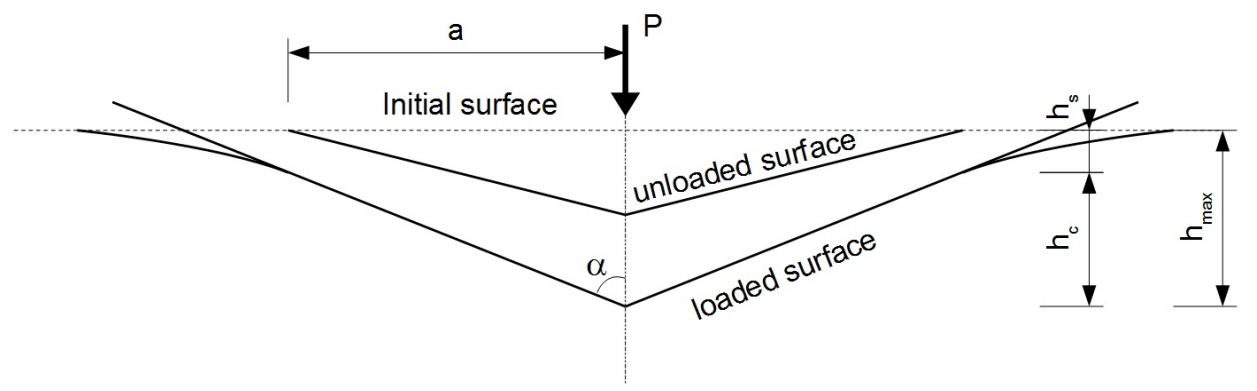

Figure 5. Scheme of the simulation under the indenter.

the material to mechanical loading, in particular the relation between the loading force and the depth of penetration. Loading diagram (Figure 6) of standard controlled load test of an individual indent consisted of three segments: loading on maximum force Fn, holding at the peak and unloading. Applied load force was in three steps with. Speed of loading and unloading force was $40 / 40 \mathrm{mN} / \mathrm{min}$ and $80 / 80 \mathrm{mN} / \mathrm{min}$ [14]. The reduced modulus can be related to the sample Young's modulus E using the derived relations [9, 15].

For forces $<12 \mathrm{mN}$, indents were standard, with no evidence of brittle fracture. The dispersion of values is about $10 \%$, which is acceptable due to the not completely smooth sample and the nature of the analyzed material. Results in form of hardness and modulus of elasticity (Table 1) are for indentation at the cross-section of the fiber. Evaluation of the mechanical properties in the longitudinal section was complicated by the high fiber hardness and their orientation. There has often been a shift of the indentor tip outside the surveyed area

\section{Conclusion}

The presented results obtained by the static indentation in form of modulus of elasticity (Table 1) are $26.0 \pm 2.3 \mathrm{GPa}$ and hardness is $3.60 \pm 0.35 \mathrm{GPa}$. The values are reasonable with respect to the properties of carbon fibers [6, 7]. It has been found that with a loading force greater than $12 \mathrm{mN}$, a brittle fracture of fibers occurs (Figure 7) and it is not possible to determine the required values at these forces and the results are misleading and disorted. However, the results from the lower load stages are almost constant and are usable. In the next work, these nanoindentation results will be compared to the macromechanical properties of carbon fiber fabric and micromechanical properties od timber.

\section{ACKNOWLEDGEMENTS}

The financial support of this outcome by the Faculty of Civil Engineering, CTU in Prague (SGS project No. SGS17/168/OHK1/3T/11 and No. SGS16/201/OHK1/3T/11) and by the Ministry of Education, Youth and Sports within National Sustainability Programme I, project No. LO1605 is gratefully acknowledged. The authors also thank the Center for Nanotechnology in Civil Engineering at the Faculty of Civil Engineering, Czech Technical University in Prague, and the Joint Laboratory of Polymer Nanofiber Technologies of the Institute of Physics, Academy of Science of Czech Republic, and the Faculty of Civil Engineering, Czech Technical University in Prague. Special thanks also go to company DEKTRADE s.r.o. for providing us with GLT beams and to company GRM systems for providing carbon fiber fabric. 


\begin{tabular}{l|ccc}
\hline Loading force [mN] & 5 & 10 & 15 \\
Loading/unloading speed [mN/min] & $40 / 40$ & $80 / 80$ & $80 / 80$ \\
\hline Hardness [GPa] & $\sim 3.6$ & $\sim 3.7$ & $\sim 1.0^{*}$ \\
Standard error of Hardness & 0.32 & 0.39 & 0.18 \\
\hline Modulus of elasticity Hr [GPa] & $\sim 26$ & $\sim 26$ & $\sim 13^{*}$ \\
Standard error of Modulus of elasticity & 2.1 & 2.5 & 0.6 \\
\hline Contact depth hc [nm] & $\sim 570$ & $\sim 810$ & $\sim 1970^{*}$ \\
Standard error of contact depth & 28 & 37 & 90 \\
\hline \hline Note & $*$ For the vast majority of indentations \\
& the fiber has broken through the fracture \\
& the resulting value is misleading and distorted \\
\hline
\end{tabular}

TABLE 1. The results of indentations in the cross-section of the fibers - indented in the direction of the longitudinal axis of the fiber.

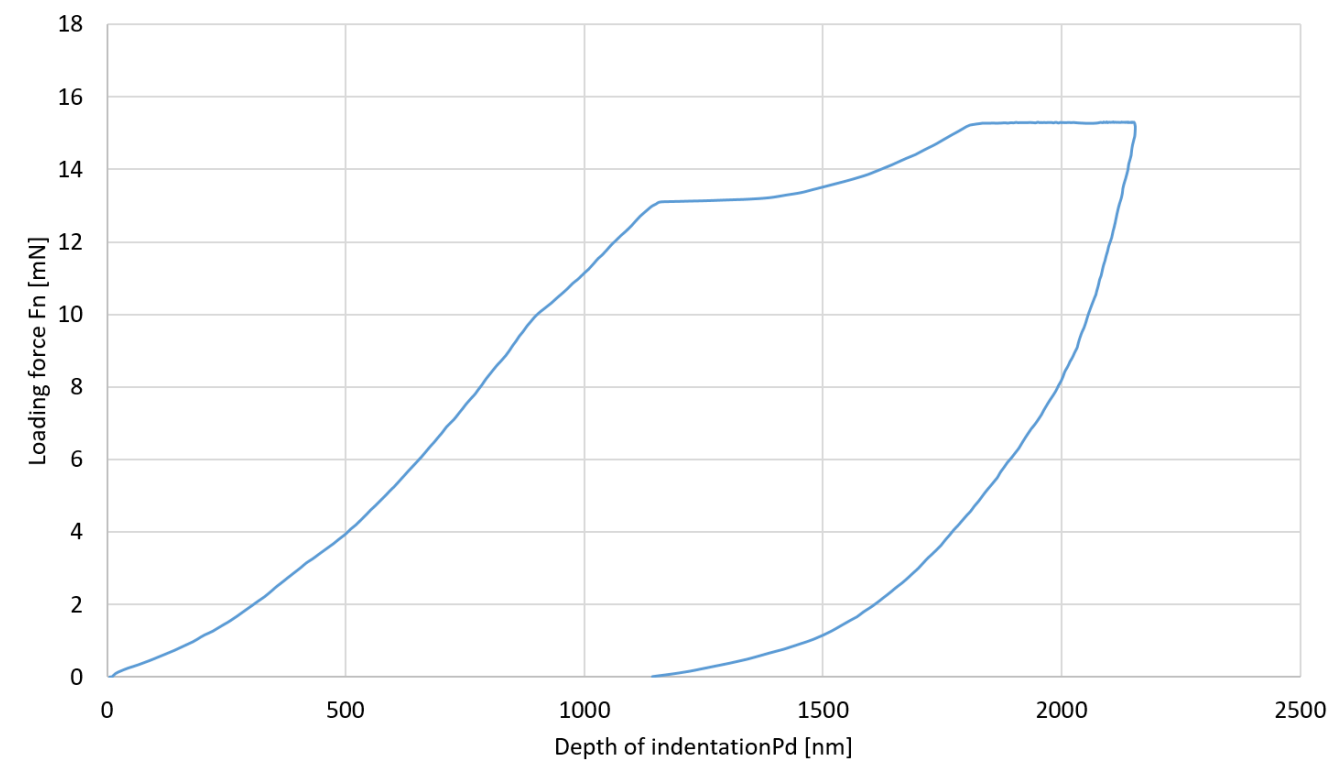

Figure 6. Typical indentation curves for forces greater than $12 \mathrm{mN}$ causing fracture failure in the sample.

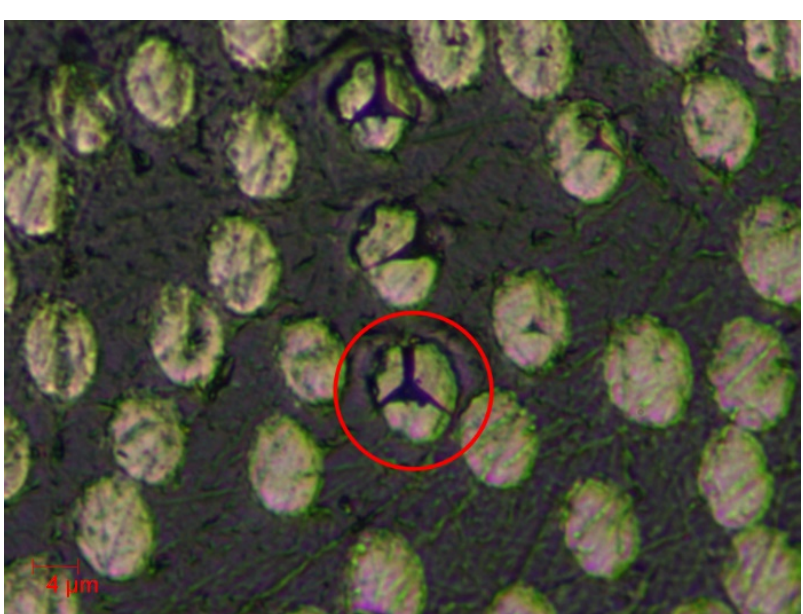

FiguRE 7. Image from the optical microscope of the broken fiber.

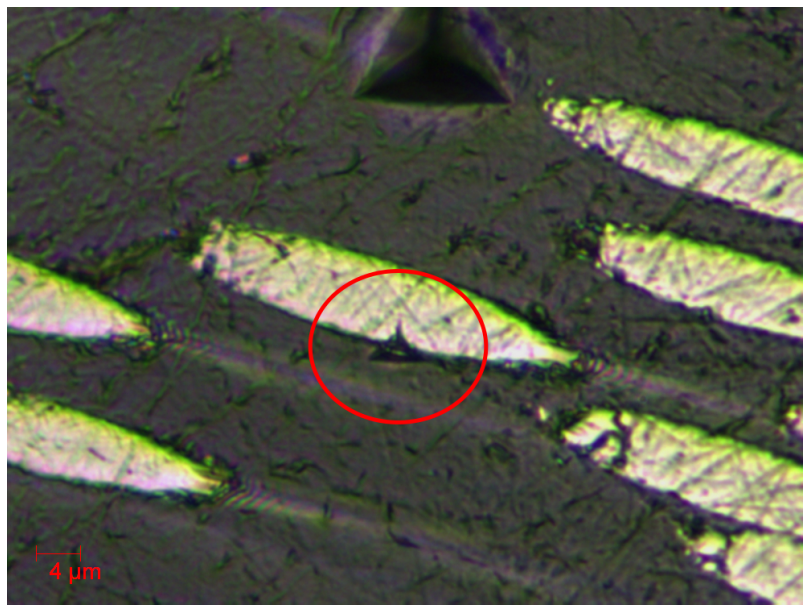

Figure 8. A sample of indent outside the fiber cut section. Note: This is not a pure longitudinal cut, but a diagonal cut. 


\section{REFERENCES}

[1] R. Bergman, Z. Cai, C. G. Carll, et al. Wood handbook, wood as an engineering material (all chapters). forest products laboratory. wood handbook-wood as an engineering material. General Technical Report FPLGTR-190 Madison, WI: US Department of Agriculture, Forest Service, Forest Products Laboratory 2010.

[2] V. Angst. Handbook 1: Timber structures 2008.

[3] P. Klapálek, Z. Prošek, V. Králík. Comparison of modulus of elasticity of glued laminated timber. In Key Engineering Materials, vol. 714, pp. 29-32. Trans Tech Publ, 2016.

[4] Z. Prošek, J. Topič, P. Tesárek, et al. Micromechanical properties of spruce tissues using static nanoindentation and modulus mapping. In Applied Mechanics and Materials, vol. 732, pp. 115-118. Trans Tech Publ, 2015.

[5] S. Syed Asif, K. Wahl, R. Colton, O. Warren.

Quantitative imaging of nanoscale mechanical properties using hybrid nanoindentation and force modulation. Journal of Applied Physics 90(3):1192-1200, 2001.

[6] Y. Deng. Carbon fiber electronic interconnects. Ph.D. thesis, University of Maryland, College Park, 2007.

[7] J. Gorss. High performance carbon fibers national historic chemical landmarks.

[8] S. S. Asif, K. Wahl, R. Colton. Nanoindentation and contact stiffness measurement using force modulation with a capacitive load-displacement transducer. Review of scientific instruments 70(5):2408-2413, 1999.
[9] A. Fisher-Cripps. Nanoindentation, 2002. New York, SpringerVerlag .

[10] H. Hertz. Über die berührung fester elastischer körper und über die härte-verhandlungen des vereins zur beförderung des gewerbefleißes 1882 .

[11] I. N. Sneddon. The relation between load and penetration in the axisymmetric boussinesq problem for a punch of arbitrary profile. International journal of engineering science 3(1):47-57, 1965.

[12] I. W. Bailey, T. Kerr. The visible structure of the secondary wall and its significance in physical and chemical investigations of tracheary cells and fibers. Journal of the Arnold Arboretum 16(3):273-300, 1935.

[13] Z. Prošek, V. Králík, J. Topič, et al. Microstructure description and micromechanical properties of spruce wood. Acta Polytechnica 55(1):39-49, 2015.

[14] P. Hájková, A. Jíra. Micromechanical analysis of complex structures by nanoindentation. In Applied Mechanics and Materials, vol. 731, pp. 60-65. Trans Tech Publ, 2017.

[15] Z. Prošek, J. Topič, P. Tesárek, et al. Micromechanical properties of spruce tissues using static nanoindentation and modulus mapping. In Applied Mechanics and Materials, vol. 732, pp. 115-118. Trans Tech Publ, 2015. 